\title{
Model and simulation of multi-functional variable refrigerant flow systems in EnergyPlus
}

\author{
Maria Muñoz de la Peña ${ }^{1}$, Luca Molinaroli ${ }^{1, *}$, Barbara Torregrosa ${ }^{2}$, and Gaspar Paya ${ }^{2}$ \\ ${ }^{1}$ Department of Energy, Politecnico di Milano, Milano, Italy \\ ${ }^{2}$ CYPE Ingenieros S.A, Alicante, Spain
}

\begin{abstract}
The multi-functional variable refrigerant flow (MFVRF) system is a promising solution to meet the UE objective that all new buildings shall be nearly zero-energy buildings (NZEBs). In particular, it is a high-efficiency system able to supply space cooling, space heating and domestic hot water (DHW) production simultaneously in different zones allowing also for waste heat recovery. The aim of this work is to implement a novel dynamic model of the MFVRF in EnergyPlus 9.4 in order to assess its final energy consumption and to account for the heat recovered when working in cooling mode to be used for DHW production. The developed model is employed to compare the performance of a MFVRF system in a multifamily residential building of $858 \mathrm{~m} 2$ with that of a conventional solution. The simulations are performed for two different climate conditions in Spain and two different DHW consumption temperatures. The results show significant energy savings achieved with the MFVRF system and DHW being consumed at $60{ }^{\circ} \mathrm{C}$ for both Madrid $(63.82 \%)$ and Seville (51.8\%). Additionally, energy savings were even further enhanced for DHW being consumed at $45{ }^{\circ} \mathrm{C}$ for Madrid (73.69\%) and for Seville $(70.71 \%)$. It is concluded that part of the annual DHW energy demand is covered by heat recovery for Madrid (4.96\%) and Seville $(5.69 \%)$ at a DHW consumption temperature of $60{ }^{\circ} \mathrm{C}$ and for Madrid $(6.42 \%)$ and Seville $(8.96 \%)$ at a DHW consumption temperature of $45^{\circ} \mathrm{C}$.
\end{abstract}

\section{INTRODUCTION}

The construction and use of buildings are responsible for over one-third of global final energy consumption and nearly $40 \%$ of total direct and indirect $\mathrm{CO}_{2}$ emissions [1].

The 2010 Energy Performance of Buildings Directive (EPBD) [2] and the 2012 Energy Efficiency Directive [3] are the main policies in the European Union that aim to achieve highly energy efficient and decarbonized building stock by 2050 . Specifically, it is stated in article 9 of the EPBD that all new buildings must be nearly zero-energy buildings (NZEB). To do so, it is also referred in article 6 of the EPBD that high efficiency alternatives shall be ensured in new buildings in order to reduce the final energy consumption in buildings. The variable refrigerant flow (VRF) heat pump systems can be a promising solution in order to achieve the EU energy efficiency goals. In general, VRF systems are able to supply individualized thermal comfort to the multiple zones of a building by using a variable speed compressor, variable speed fans and electronic expansion valves (EEVs) in every indoor 
unit, which make them work at an exceptional part load efficiency due to the wide capacity modulation [4].

More specifically, the so-called multi-functional variable refrigerant flow (MFVRF) system is able to provide simultaneous heating, cooling and domestic hot water (DHW) production and, in addition, allows the heat recovery (HR) among the different units thanks to the heat recovery unit (HRU). This feature is particularly interesting when operating in cooling mode, as the waste heat generated during the cycle can be used for DHW production.

Indeed, assessing the share of the DHW that can be covered by heat recovery is of great interest in order to meet the regulatory framework that stablishes the requirements to be met by buildings, such as, CTE HE 4 [5] in the case of Spain.

Relevant studies on the performance of MFVRF systems have been found in the literature. Ji et al. [6], experimentally evaluated the coefficient of performance (COP) of a MFVRF system when working in the cooling season with water-heating plus heating, water-heating only, and heating only operation mode. The resulting COPs where 4.02, 3.25 and 2.72 , respectively. The result shows that the combination of water-heating and airconditioning (AC) solutions leads to a much more efficient system.

Shao et al. [7], performed an experimental study on an inverter driven AC heat pump system with water-heating under five different operation modes: cooling-only, cooling with water-heating, heating-only, heating with water-heating and water-heating only. It was concluded that energy efficiency ratio (EER) of the system in cooling with DHW production and heating with DHW production mode were $90 \%$ and $10 \%$ higher than those in the cooling-only and heating-only operation modes, respectively.

Jiang et al. [8] proposed and applied the EEV control scheme of multifunction-al heat pump system. They reported that the COPs of the system were 4.1 and 3.3 in the waterheating only and radiant floor heating modes, respectively. They also showed that the COP of the system in the space cooling and water-heating mode was $9 \%$ higher than that of the system operated in the space cooling-only operation mode.

Relevant studies on computational models of VRF systems have been found in the literature. Most of them employ EnergyPlus ${ }^{\mathrm{TM}}$ [9], a building energy simulation program used to model energy consumption for heating, cooling, ventilation, lighting and plug and process load and water use in buildings. Zhou et al. [10], proposed a schematic flowchart of the air-cooled VRF system modelling in EnergyPlus ${ }^{\mathrm{TM}}$. They rearranged pre-existing modules in EnergyPlus ${ }^{\mathrm{TM}}$, such as the direct expansion (DX) coil, in order to model the VRF system and build an energy simulation environment. In an extension of this work, the authors presented the mathematical model of a VRF system and validated it against experimental data under cooling conditions [11].

Based on the previous model, Li et al. [12], developed a simulation module for watercooled VRF systems in EnergyPlus ${ }^{\mathrm{TM}}$. The module was linked with the cooling tower, condenser's cooling water pump and fan modules, and thus dynamic simulation of all main equipment in the whole system can be performed simultaneously. The HR capability was included [13] as an enhancement of the previously developed model [12].

Raustad [14], developed the first heat pump variable refrigerant flow (HPVRF) built-in module included in EnergyPlus ${ }^{\mathrm{TM}}$. The model is based in an empirical equation fit model based on manufacturers' performance data. This HPVRF computer model provides either cooling or heating but does not simulate HR mode. The model was validated an implemented in EnergyPlus ${ }^{\mathrm{TM}}$ version 7.2. The model is referred as the System curve-based model (VRF-SysCurve) in EnergyPlus ${ }^{\mathrm{TM}}$.

A new model to simulate the energy performance of VRF systems in the heat pump (HP) operation mode was introduced by Hong et al. [15]. Compared with the HPVRF model by Raustad [14], the new HPVRF system model had more component models based 
on physics and thus results showed that the model provided more accurate estimate of the HPVRF system performance. Nevertheless, the data required by this innovative HPVRF model is not usually available from manufacturers. The model was validated an implemented in EnergyPlus ${ }^{\mathrm{TM}}$ version 8.4. The model is referred as the physics-based model (VRF-FluidTCtrl) in EnergyPlus ${ }^{\mathrm{TM}}$.

Recently, a novel model to simulate the energy performance of VRF systems with HR configurations which is capable of achieving HR from cooling zones to heating zones and providing simultaneous zone cooling and heating operations was developed by Zhang et al. [16]. The model was validated and implemented in EnergyPlus ${ }^{\mathrm{TM}}$ version 8.6.

No previous model analyzing the performance of the MFVRF system could be found in the literature. Therefore, it is currently not possible to perform dynamic energy simulations of a building equipped with a MFVRF system in order to predict its performance.

The objective of this work is to develop a novel model for the MFVRF system in EnergyPlus $^{\mathrm{TM}}$ version 9.4 .0 so that the energy performance of the integrate solution of the MFVRF system can be evaluated. Besides, model will serve to account for the re-coverable heat while operating in cooling mode that is actually employed for DHW pro-duction. Therefore, it will be possible to quantify the share of the DHW energy demand that can be covered by HR.

The developed model is then employed to compare via simulation in EnergyPlus ${ }^{\mathrm{TM}}$ a multifamily residential building equipped with a traditional HVAC and DHW production system with the integrated solution of the MFVRF system in order to assess the overall energy savings achieved by the last one.

\section{MATERIALS AND METHODS}

VRF system is an AC system composed of an outdoor unit (OU) connected to up to 64 indoor units (IUs) of different capacities located in each thermal zone of the building enabling individualized thermal comfort, simultaneous heating and cooling in different thermal zones and HR from one IU to another.

The system can adjust the refrigerant flow rate, and thus the capacity, to meet the space cooling and heating demand through the variable speed compressor located in the OU and the EEVs located in each IU. VRF systems integrate a four-way valve that helps to reverse the direction of the cycle so that the system can work in heating or cooling mode as demanded.

MFVRF systems include a DHW production unit, also referred as hydrokit. There are two different DHW production units available in the market: the low temperature module and the high temperature module. For the first type, the DHW production unit is connected in series to the rest of IUs and chilled and hot water can be produced in a temperature range of $5-45^{\circ} \mathrm{C}$. For the second type, the DHW production unit consists of a second refrigerant cascade cycle with an additional compressor and DHW can be produced in a temperature range of $25-80^{\circ} \mathrm{C}$.

This section includes the description of the proposed method for modelling the MFVRF system in EnergyPlus ${ }^{\mathrm{TM}}$. The improvement achieved with respect to the existing model of VRF systems is the ability to include a DHW production unit, so that the integrate solution of the system providing heating, cooling and DHW production while re-covering heat can be evaluated.

The performance of a MFVRF system in a multifamily residential building is then analyzed under two different climates and two DHW consumption temperatures.

\subsection{MFVRF system model}


The model developed in this work is aimed to simulate MFVRF systems connected to a low-temperature indoor DHW production unit. To do so, some of the objects currently available in EnergyPlus ${ }^{\mathrm{TM}}$ version 9.4 are rearranged in order to model the MFVRF system performance. The limitation of the existing VRF model in EnergyPlus ${ }^{\mathrm{TM}}$ is that it does not include the possibility of producing chilled and hot water in the IUs and therefore, it does not allow the direct connection of an IU for DHW production. However, the whole energy demand of the MFVRF system must be considered dynamically in order to calculate the actual part load ratio of the outdoor unit, which is key for determining the energy consumption of the system, as well as to evaluate the heat recovery performance. In order to overcome this limitation, an approach consisting in two separate simulations of the building is proposed.

In the first step, the DHW energy demand of the building is calculated. To do so, the building equipped with a DHW storage tank is modelled. The WaterHeater: Stratified object available in EnergyPlus ${ }^{\mathrm{TM}}$ is the main model that is included in this first simulation. Water thermal tank objects are used for storing and heating water in EnergyPlus ${ }^{\mathrm{TM}}$. The main motivation for using the stratified tank model and not any of the other storage tank models available in EnergyPlus ${ }^{\mathrm{TM}}$ is that it offers the possibility of introducing two heating elements and a better modelling of thermal storage applications which rely on stratification, that is, with the top of the tank hotter than the bottom, to im-prove heating performance. The use of two water heaters is essential for the purpose of this work, since it is necessary to model both the first heat income from the VRF hydrokit (heater 1) and a second heat income from an auxiliary heater (heater 2) in the top part of the tank, which will turn on if the energy from the VRF system is not enough to cover the DHW demand or if DHW is demanded above $45^{\circ} \mathrm{C}$.

The main inputs of the model at this first step are: (a) the tank characteristics, (b) the DHW flowrate at each time-step, (c) the DHW temperature demanded in the building and (d) the water temperature entering the tank. The main output of this first simulation is the energy demand profile that has to be overcome by both the MFVRF and the auxiliary heater at each time-step.

In the second step the MFVRF system energy consumption is calculated. To do so, the curve-based AirConditioner:VariableRefrigerantFlow (VRF-SysCurve) model available in EnergyPlus $^{\mathrm{TM}}$ is used with some particularities. Since the existing VRF system model object in EnergyPlus ${ }^{\mathrm{TM}}$ does not allow the connection of an IU for DHW production, the input of this second simulation is directly the DHW energy demand profile obtained in the previous step. In this way, the VRF IU in charge to overcome this demand will perform as the actual hydrokit in terms of energy production. The dynamic model of the VRF system carries the information from the IUs to the OU, which will therefore calculate the energy performance of the MVRF system including the DHW production.

In order to feed the VRF model with the DHW energy demand profile, a fictitious adiabatic thermal zone is included in the $3 \mathrm{D}$ geometrical model of the building. Notice that the term fictitious is applied as the zone does not exist in the real building. Additionally, the zone is adiabatic and hermetic so that the actual temperature of the building is not disturbed. In such zone, the energy demand profile that was an output from the previous step is included as an internal heat loss. To do so, the Internal-Gain:OtherEquipment object is used as it allows the user to introduce additional sources of heat gain and losses to a thermal zone in the building. A conventional VRF IU model is placed in this fictitious zone, therefore this unit will be in charge of supplying the energy requested by the profile. By doing so, the OU of the MFVRF system accounts for the load demanded by the DHW energy demand profile so it considers it in terms of capacity, combination ratio (CR), partload ratio (PLR), power consumption and heat recovery rate (HRR). 
It is assumed that the indoor DHW production unit will work at its nominal and maximum supply temperature of $45^{\circ} \mathrm{C}$, so the effect of the variation of this temperature in the VRF system performance has been neglected in this work. Besides, the load from the DHW production unit will usually represent a small part of the total heating load in the OU.

The main inputs of the model are: (1) the indoor and outdoor air conditions, (2) the performance data of the VRF heat pump OU, (3) the performance data of the VRF heat pump IUs connected to the $\mathrm{OU}$ and (4) the losses associated with the refrigerant distribution piping [9]. These performance characteristics are typically found in manufacturers' literature. The main output is the MFVRF system consumption for heating, cooling and DHW production. Besides, it is possible to obtain the HRR and to calculate the share of the DHW demand that can be covered by HR.

\subsection{Multifamily housing study}

The developed model is used to assess the final energy consumption of a building equipped with the integrated solution of the MFVRF system. The results will be com-pared with those of a conventional solution for two different locations in Spain: Madrid (D3) and Seville (B4) and two different DHW consumption temperatures.

According to the Spanish Building Code [5], it is possible to define for each location a climatic zone indicated by a letter from A to $\mathrm{E}$, corresponding to the winter climate characteristics, and a number from 1 to 4 , corresponding to the summer cli-mate characteristics, being $\mathrm{A}$ and 1 the less severe conditions. For each location, climate zone also depends on the altitude above sea level at which the site is located. Average temperatures for the climatic zones being considered for the heating (October-May) and cooling (June-September) periods are depicted in Table 1.

Table 1. Average and standard deviation of temperature.

\begin{tabular}{|c|c|c|c|c|c|c|}
\hline \multirow{2}{*}{ Location } & \multirow{2}{*}{$\begin{array}{c}\text { Altitude } \\
(\mathrm{m})\end{array}$} & \multirow{2}{*}{$\begin{array}{c}\text { Climate } \\
\text { zone }\end{array}$} & \multicolumn{2}{|c|}{ October-May } & \multicolumn{2}{|c|}{ June-September } \\
\cline { 6 - 8 } & & TAVE $\left({ }^{\circ} \mathrm{C}\right)$ & $\begin{array}{c}\text { TstD,DEV } \\
\left({ }^{\circ} \mathrm{C}\right)\end{array}$ & TAVE $\left({ }^{\circ} \mathrm{C}\right)$ & $\begin{array}{c}\text { TstD,DEV } \\
\left({ }^{\circ} \mathrm{C}\right)\end{array}$ \\
\hline Madrid & 667 & D3 & 10 & 6.05 & 23.4 & 6 \\
\hline Seville & 7 & B4 & 16.1 & 5.74 & 27.3 & 5.47 \\
\hline
\end{tabular}

Weather data together with a document explaining the content of the files, scope, and expressions of proven validity for the derivation of different climate parameters is defined in [5]. Data files for different climatic zones contain a typical years' data in hourly intervals comprising a total of 8760 lines of data. The climate conditions for Madrid and Seville locations are depicted (Fig. 1) on the psychrometric chart for the heating (blue) and cooling (red) seasons. 


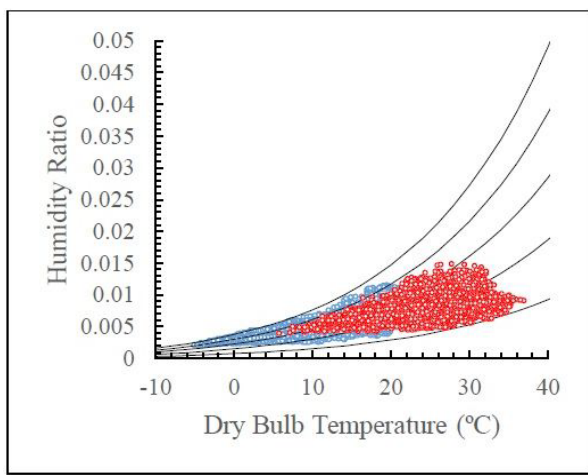

(a)

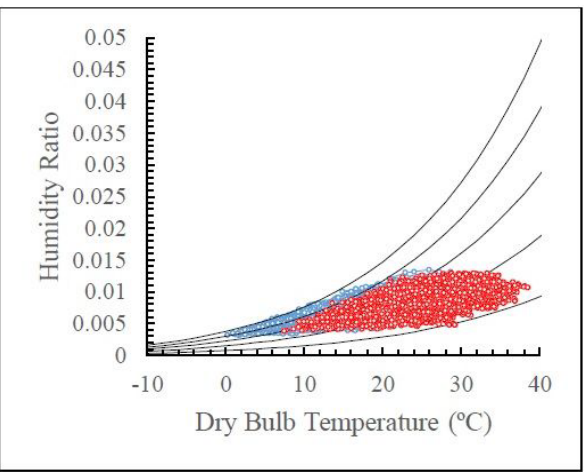

(b)

Fig. 1. Psychrometic chart for Madrid (a) and Seville (b).

The simulated building (Fig. 2) consists of a multi-family housing with 8 apartments. It comprises a total of $858 \mathrm{~m}^{2}$ distributed between communal areas, 6 flats of $89 \mathrm{~m}^{2}$ and 2 penthouses of $162 \mathrm{~m}^{2}$ on the top part. The geometry of the building was designed with the free distribution application IFC Builder [17].

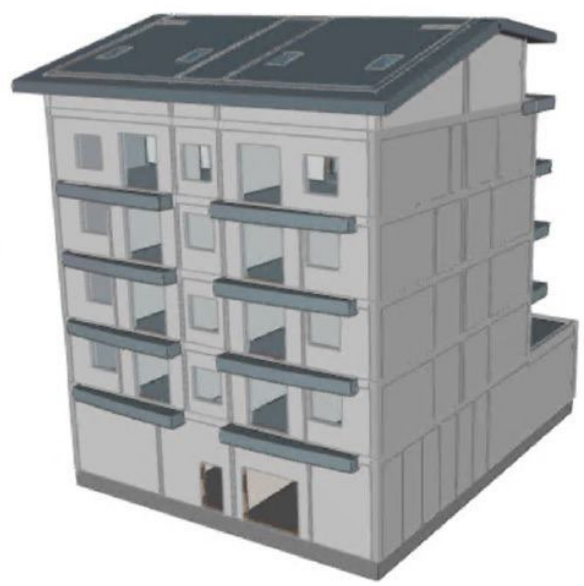

Fig. 2. Building 3D geometrical model.

The building simulation parameters have been chosen accordingly to the Spanish regulation for energy efficiency in buildings [5]. For instance, the operational conditions of conditioned spaces are those defined for residential use: a maximum indoor temperature during the cooling season $\left(25-27^{\circ} \mathrm{C}\right)$ and a minimum indoor temperature during the heating season $\left(17-20^{\circ} \mathrm{C}\right)$. Standardized profiles are also defined for internal gains due to occupation, lighting and equipment. The thermal envelope consists of a conventional solution that complies with the thermal transmittance limit values for the different climatic zones. Table 2 shows the values of the thermal transmittance of the wall and roof of the building together with the heating and cooling energy demand for Madrid and Seville.

Table 2. Thermal transmittance values and energy demand.

\begin{tabular}{|c|c|c|c|c|}
\hline \multirow{2}{*}{ Location } & \multicolumn{2}{|c|}{ Thermal Transmittance $\left(\mathrm{W} / \mathrm{m}^{2} \mathrm{~K}\right)$} & \multicolumn{2}{c|}{ Energy Demand $\left(\mathrm{kWh} / \mathrm{m}^{2} \mathrm{y}\right)$} \\
\cline { 2 - 5 } & Wall & Roof & Heating & Cooling \\
\hline Madrid & 0.25 & 0.22 & 28.5 & 8.01 \\
\hline
\end{tabular}




\begin{tabular}{|l|l|l|l|l|}
\hline Seville & 0.34 & 0.32 & 3.72 & 13.72 \\
\hline
\end{tabular}

The water mains temperature is also relevant in order to calculate the DHW production energy demand. Table 3 shows the monthly water mains average temperatures for the two locations being considered.

Table 3. Water mains average temperature. Data in $\left({ }^{\circ} \mathrm{C}\right)$.

\begin{tabular}{|c|c|c|c|c|c|c|c|c|c|c|c|c|}
\hline Location & J & F & M & A & M & J & J & A & S & O & N & D \\
\hline Madrid & 8 & 8 & 10 & 12 & 14 & 17 & 20 & 19 & 17 & 13 & 10 & 8 \\
\hline Seville & 11 & 11 & 13 & 14 & 16 & 19 & 21 & 21 & 20 & 16 & 13 & 11 \\
\hline
\end{tabular}

DHW energy demand is calculated for two different consumption temperatures: $60{ }^{\circ} \mathrm{C}$ and $45^{\circ} \mathrm{C}$. The DHW demand is obtained according to the procedure described in [3]. For residential purposes, the document proposes a $28 \mathrm{l} / \mathrm{d}$ DHW demand at a consumption temperature of $60{ }^{\circ} \mathrm{C}$ per occupant in the building.

The daily usage profile proposed in [5] for residential purposes is shown in Fig. 3 for the DHW demand at $60{ }^{\circ} \mathrm{C}$ (a) and $45^{\circ} \mathrm{C}$ (b). The profile presents a peak flow rate of the $10 \%$ of the daily water demand at 7:00 AM.

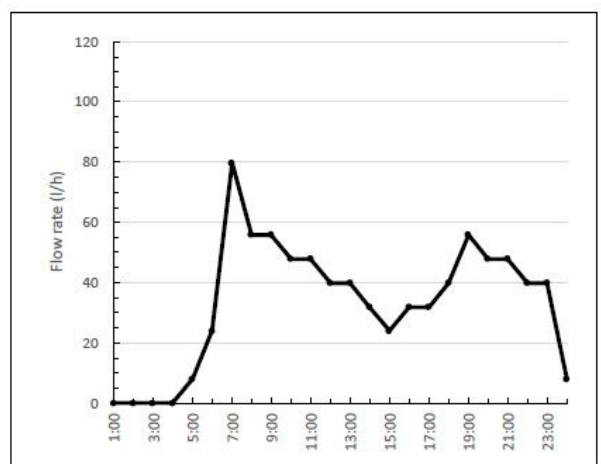

(a)

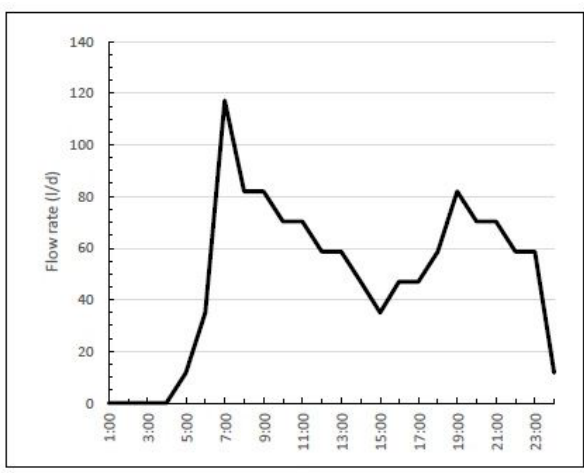

(b)

Fig. 3. Daily residential DHW use profile for DHW at $60^{\circ} \mathrm{C}$ (a) and DHW at $45^{\circ} \mathrm{C}$ (b).

The DHW energy demand of the building for the two different consumption temperatures is summarized in Table 4.

Table 4. DHW demand.

\begin{tabular}{|c|c|c|c|c|}
\hline \multirow{2}{*}{ Location } & \multicolumn{2}{|c|}{ Flow rate $(1 / \mathrm{d})$} & \multicolumn{2}{c|}{ Energy Demand $(\mathrm{kWh} / \mathrm{y})$} \\
\cline { 2 - 5 } & $45^{\circ} \mathrm{C}$ & $60^{\circ} \mathrm{C}$ & $45^{\circ} \mathrm{C}$ & $60{ }^{\circ} \mathrm{C}$ \\
\hline Madrid & 1172 & 798 & 18684.96 & 17757.00 \\
\hline Seville & 1172 & 798 & 17134.46 & 16245.11 \\
\hline
\end{tabular}

Two systems are sized, simulated and compared. The conventional solution (System A) is a central heating system composed by two gas condensing boilers, each of them providing hot water at $45^{\circ} \mathrm{C}$ to radiators in 4 different apartments. Cooling requirements are met by means of individual splits located in each apartment, conforming a total of 8 systems distributed through the whole building. The thermal efficiency of the condensing boilers is set to 0.96 . The nominal EER of each split per apartment and each split per 
duplex was set to 3.89 and 3.61, respectively, according to manufacturer's data. Besides, the gas condensing boilers provide also the heating duty necessary to cover with the DHW demand. The nominal capacity of the system was automatically sized with EnergyPlus ${ }^{\mathrm{TM}}$ and it is summarized in Table 5.

Table 5. System A nominal values.

\begin{tabular}{|c|c|c|c|}
\hline \multirow{2}{*}{ Location } & Heating power $(\mathrm{W})$ & \multicolumn{2}{|c|}{ Cooling capacity (W) } \\
\cline { 2 - 4 } & Boiler & Splits (per apartment) & Splits (per duplex) \\
\hline Madrid & 34400 & 3000 & 6000 \\
\hline Seville & 20631 & 3500 & 6100 \\
\hline
\end{tabular}

The MFVRF system (System B) consists of an air-to-air heat pump composed by a single outdoor unit and 8 ducted indoor units located in each dwelling that provide heating and cooling as shown in Table 6 . The performance data of the VRF system has been taken from a manufacturer available in the building simulation software CYPETHERM HE Plus [17] based in EnergyPlus ${ }^{\mathrm{TM}}$. Besides, this system contains a DHW production unit to cover the DHW demand of the whole building.

Table 6. System B nominal values.

\begin{tabular}{|c|c|c|c|c|c|}
\hline \multirow{2}{*}{ Location } & \multirow{2}{*}{ Equipment } & \multicolumn{2}{|c|}{ Heating } & \multicolumn{2}{|c|}{ Cooling } \\
\hline & & Q мом $(\mathrm{W})$ & $\mathrm{COP}_{\mathrm{NOM}}$ & QNOM $(\mathrm{W})$ & EERNOM \\
\hline \multirow{4}{*}{ Madrid } & OU & 45000 & 4.21 & 40000 & 3.70 \\
\hline & $\begin{array}{c}\text { IU (per } \\
\text { apartment) }\end{array}$ & 4200 & - & 3600 & - \\
\hline & $\begin{array}{l}\text { IU (per } \\
\text { duplex) }\end{array}$ & 8000 & - & 7300 & - \\
\hline & IU (Hydrokit) & 8000 & - & 9000 & - \\
\hline \multirow{4}{*}{ Seville } & OU & 45000 & 4.21 & 40000 & 3.70 \\
\hline & $\begin{array}{c}\text { IU (per } \\
\text { apartment) }\end{array}$ & 2500 & - & 4500 & - \\
\hline & $\begin{array}{l}\text { IU (per } \\
\text { duplex) }\end{array}$ & 4000 & - & 8500 & - \\
\hline & IU (Hydrokit) & 8000 & - & 9000 & - \\
\hline
\end{tabular}

Both systems are connected to a water storage tank where water is finally delivered at the consumption temperature. The storage tank is sized in accordance with the technical guidance for central DHW [18].

Since the maximum temperature at which System B can heat the DHW in the tank is 45 ${ }^{\circ} \mathrm{C}$, an auxiliary heater is required to meet the DHW demand above this temperature limit. On Figure 4 the energy demand that has to be meet by System A and System B is depicted. Notice that for DHW demand at $60{ }^{\circ} \mathrm{C}$, the auxiliary heater is activated for system $\mathrm{B}$, while it remains off for DHW demand at $45^{\circ} \mathrm{C}$ 


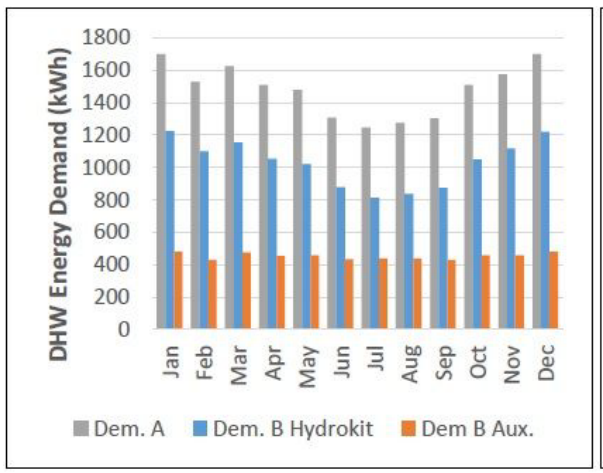

(a.1)

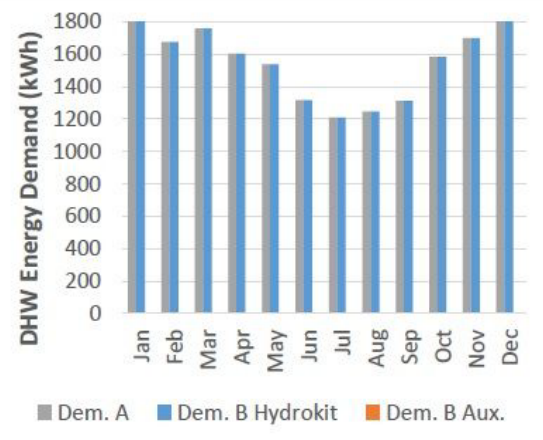

(a.2)

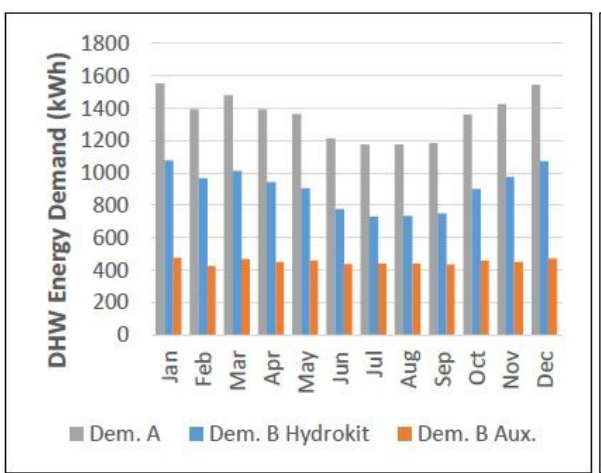

(b.1)

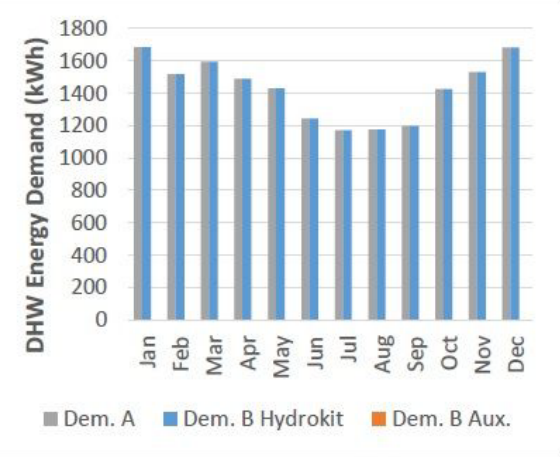

(b.2)

Fig. 4. DHW Energy demand for Madrid at $60{ }^{\circ} \mathrm{C}$ (a.1), for Madrid at $45^{\circ} \mathrm{C}$ (a.2), for Seville at $60{ }^{\circ} \mathrm{C}$ (b.1) and for Seville at $45^{\circ} \mathrm{C}$ (b.2).

On Figure 5 temperature stratification inside the tank used by system B is depicted for two different locations and two different DHW consumption temperatures. Notice that the temperature in the bottom part of the tank (Node 4) varies through the year as it depends on the water mains temperature. It can be verified that DHW is delivered at the consumption temperature of $60^{\circ} \mathrm{C}$ or $45^{\circ} \mathrm{C}$ while the average temperature of the tank is lower. 


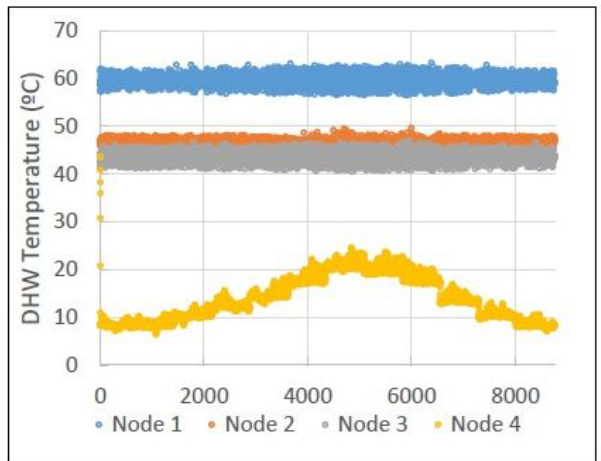

(a.1)

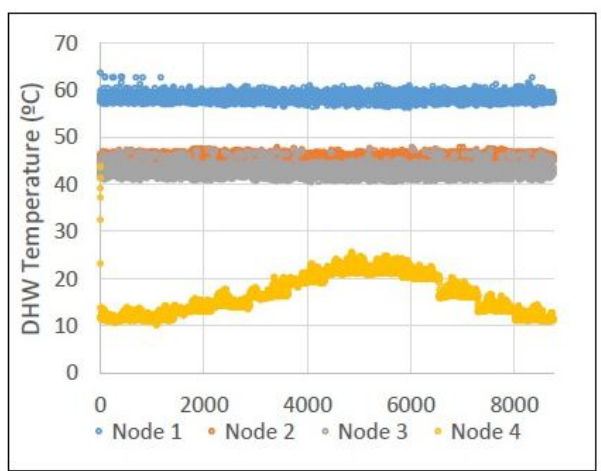

(b.1)

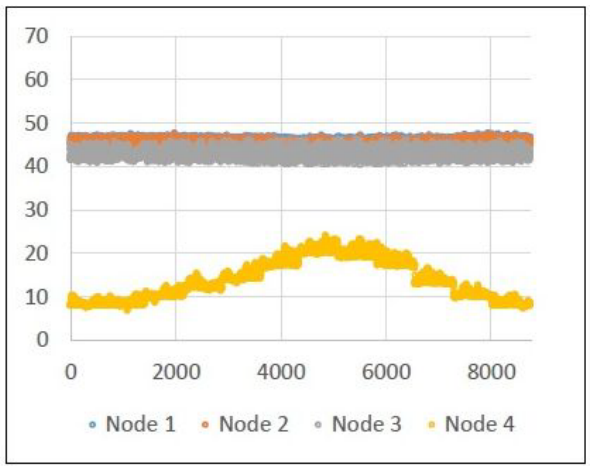

(a.2)

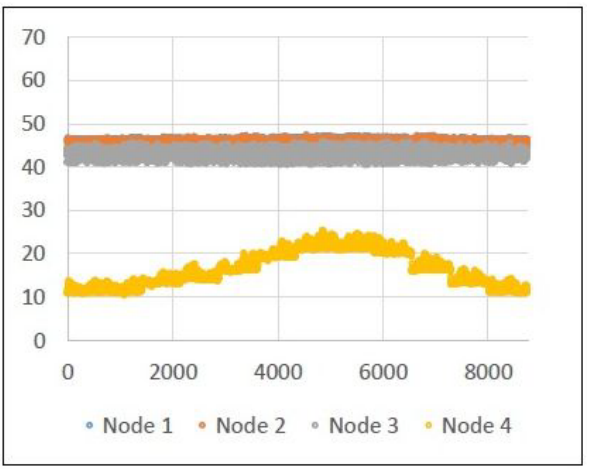

(b.2)

Fig. 5. Tank temperature stratification for Madrid at $60{ }^{\circ} \mathrm{C}$ (a.1), for Madrid at $45^{\circ} \mathrm{C}$ (a.2), for Seville at $60{ }^{\circ} \mathrm{C}$ (b.1) and for Seville at $45^{\circ} \mathrm{C}$ (b.2).

On Figure 6 the heating rate profile for both the DHW production unit of the VRF system (heater 1) and the auxiliary heater (heater 2) is depicted together with the flow rate profile for a typical 24-hour time period. For this tank characteristics, heating rate peak coincides with the DHW demand peak.

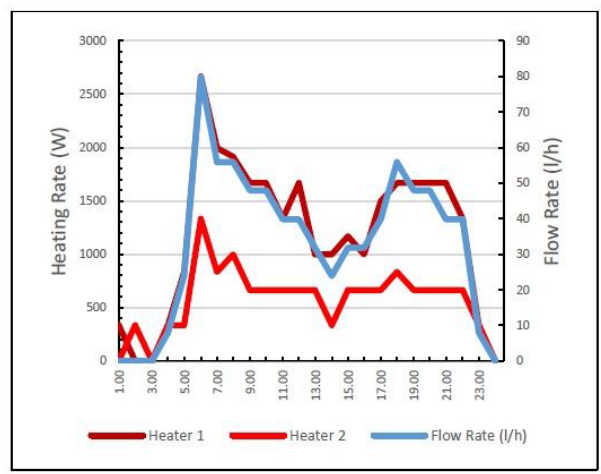

(a)

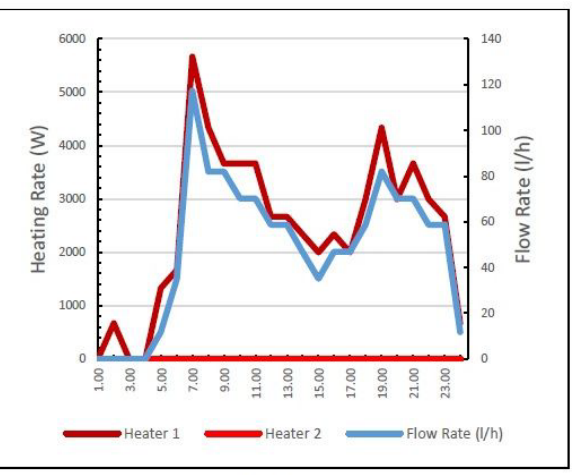

(b)

Fig. 6. Heating rate profile for (a) DHW consumption at $60^{\circ} \mathrm{C}$ and (b) DHW consumption at $45^{\circ} \mathrm{C}$.

\section{RESULTS}


A total of 8 simulations have been conducted in EnergyPlus ${ }^{\mathrm{TM}}$ version 9.4.0 in order to compare the conventional solution (System A) and the MFVRF (System B). Both systems have been simulated in two different locations, Madrid and Seville, to analyse the influence of climatic conditions. Besides, the comparison has been carried out considering two different DHW consumption temperatures, $45^{\circ} \mathrm{C}$ and $60{ }^{\circ} \mathrm{C}$, in order to study the influence of this parameter in the global energy consumption of the systems.

Figure 7 shows the monthly cooling, heating and DHW demand and consumption for (a.1) Madrid (60 $\left.{ }^{\circ} \mathrm{C}\right)$; (a.2) Madrid $\left(45^{\circ} \mathrm{C}\right)$; (b.1) Seville $\left(60^{\circ} \mathrm{C}\right)$; and (b.2) Seville $\left(45^{\circ} \mathrm{C}\right)$. The continental climate in Madrid (C3), with an average temperature of around $35^{\circ} \mathrm{C}$ in the summer season and a temperature of around $-5^{\circ} \mathrm{C}$ in the winter season, causes high heating and cooling demands. The climate in Seville (D4), however, results in a much lower heating demand, although due to the high temperatures reached in the summer months, the cooling demand is even higher than in the case of Madrid.

The SCOP of the system is 3.91 in the case of Madrid and 4.13 in the case of Seville. The value oscillates between 3.18 for the coolest months and increases up to 4.43 for the highest outdoor temperatures. For the same time period, values in Seville are higher, as the outdoor temperature is also higher.

The SEER of the system is 6.18 in the case of Madrid and 5.53 in the case of Seville. Monthly values range between 6.00 and 6.88 for Madrid and are slightly lower in the case of Seville, ranging between 5.04 and 6.10 .

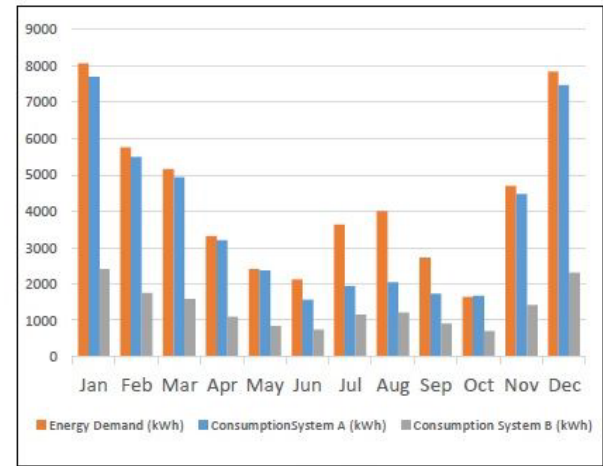

(a.1)

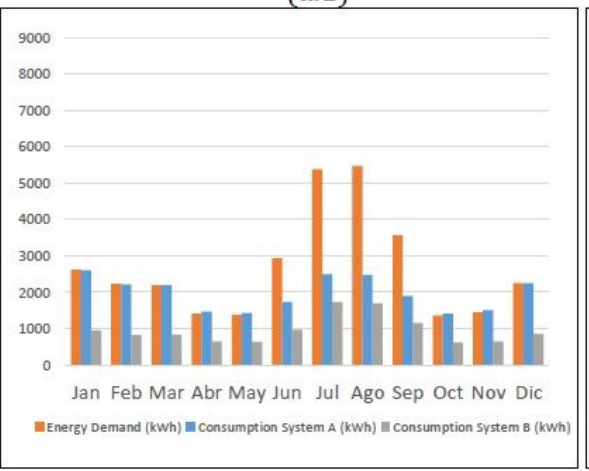

(b.1)

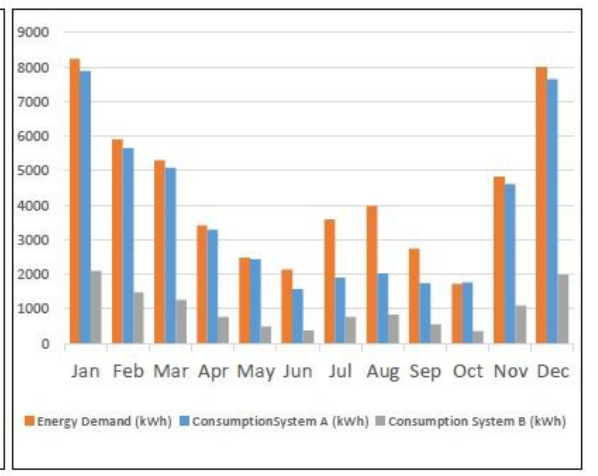

(a.2)

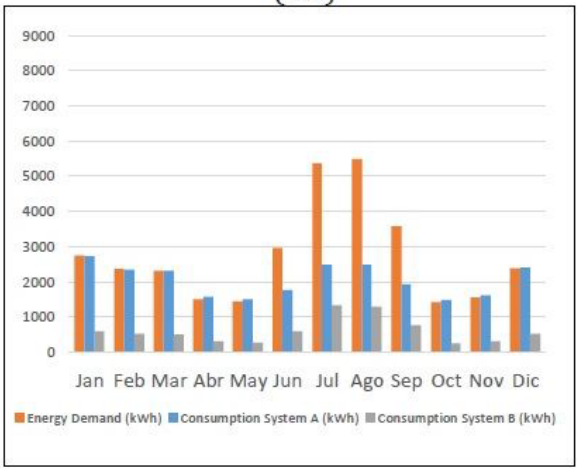

(b.2)

Fig. 7. Heating, cooling and DHW energy demand and consumption for Madrid with DHW at $60{ }^{\circ} \mathrm{C}$ (a.1); for Madrid with DHW at $45^{\circ} \mathrm{C}$ (a.2); for Seville with DHW at $60^{\circ} \mathrm{C}$ (b.1) and for Seville with DHW at $45^{\circ} \mathrm{C}$ (b.2). 
The numerical results of the energy demand and consumption of both systems at both DHW consumption temperatures are summarized in Table 7. As expected, MFVRF system consumes significantly less energy than the traditional condensing boiler plus individual splits system. While cooling consumption is similar for both systems, as they are based on the same technology, remarkable improvements are achieved in terms of heating and DHW production energy consumption. Specifically, the energy savings achieved with system B and DHW consumption at $60{ }^{\circ} \mathrm{C}$ are $63.82 \%$ for Madrid and $51.30 \%$ for Seville. Additionally, when the DHW is consumed at $45{ }^{\circ} \mathrm{C}$, the energy savings are further improved: $73.69 \%$ for Madrid and $70.71 \%$ for Seville. The savings are higher in Madrid due to the higher heating demands. Moreover, the results improve for a lower DHW consumption temperature, as System B is capable of supplying the entire DHW demand without the usage of an auxiliary heater.

Table 7. Energy consumption.

\begin{tabular}{|c|c|c|c|c|c|c|c|c|}
\hline \multirow{2}{*}{ Location } & \multicolumn{4}{|c|}{ Consumption system A $\left(\mathrm{kWh} / \mathrm{m}^{2}\right)$} & \multicolumn{3}{c|}{ Consumption system B $\left(\mathrm{kWh} / \mathrm{m}^{2}\right)$} \\
\cline { 2 - 9 } & Heating & Cooling & $\begin{array}{c}\text { DHW } \\
\left(45^{\circ} \mathrm{C}\right)\end{array}$ & $\begin{array}{c}\text { DHW } \\
\left(60^{\circ} \mathrm{C}\right)\end{array}$ & Heating & Cooling & $\begin{array}{c}\text { DHW } \\
\left(45^{\circ} \mathrm{C}\right)\end{array}$ & $\begin{array}{c}\mathrm{DHW} \\
\left(60^{\circ} \mathrm{C}\right)\end{array}$ \\
\hline Madrid & 28.2 & 2.28 & 22.68 & 21.55 & 7.5 & 2.17 & 4.29 & 9.16 \\
\hline Seville & 3.62 & 4.26 & 20.8 & 19.72 & 0.9 & 4.00 & 3.47 & 8.54 \\
\hline
\end{tabular}

When evaluating DHW consumption individually, System B achieves a reduction in energy consumption of $57.49 \%$ for Madrid and $56.69 \%$ for Seville for a DHW consumption temperature of $60{ }^{\circ} \mathrm{C}$ and a reduction in energy consumption of $81.08 \%$ for Madrid and $83.32 \%$ for Seville for a DHW consumption temperature of $45^{\circ} \mathrm{C}$. As can be observed, the reduction in DHW energy consumption obtained with System B is larger as the DHW consumption temperature values are reduced.

In Figure 8, DHW energy consumption is separated from energy consumption for heating and air-conditioning in order to evaluate the weight of DHW energy consumption in the total system consumption and to evaluate the benefits of heat recovery for DHW energy consumption. 


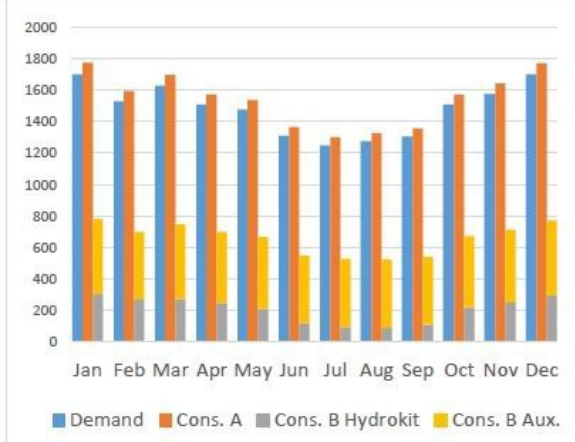

(a.1)

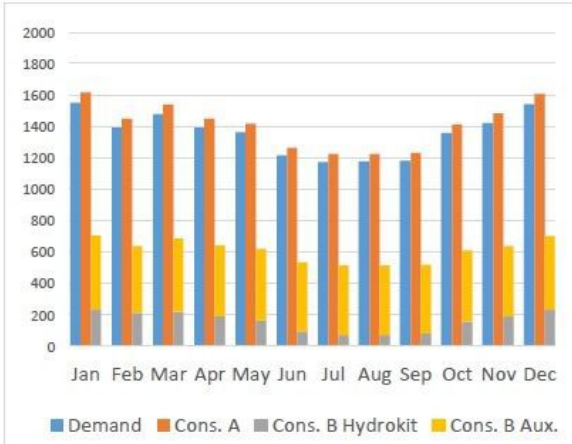

(b.1)

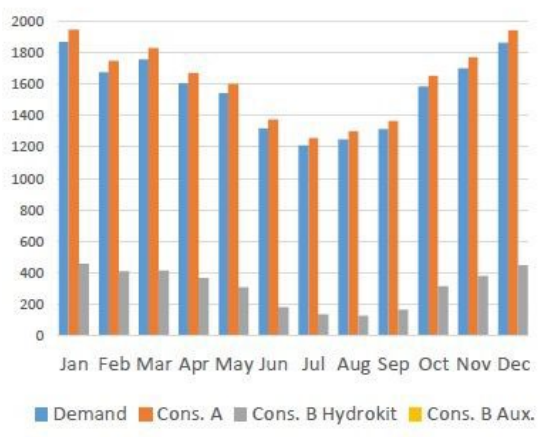

(a.2)

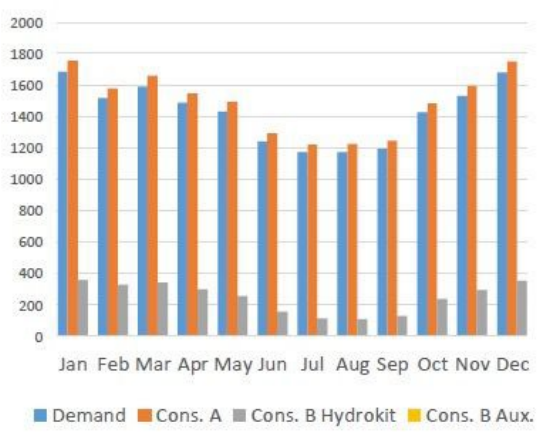

(b.2)

Fig. 8. DHW energy demand for Madrid with DHW at $60^{\circ} \mathrm{C}$ (a.1); for Madrid with DHW at $45^{\circ} \mathrm{C}$ (a.2); for Seville with DHW at $60{ }^{\circ} \mathrm{C}$ (b.1) and for Seville with DHW at $45^{\circ} \mathrm{C}$ (b.2).

For system B, the DHW consumption at $60{ }^{\circ} \mathrm{C}$ represents the $48.65 \%$ and $63.53 \%$ of the total energy consumption for Madrid and Seville, respectively. Overall, the MFVRF system is able to recover a $10.5 \%, 20.11 \%, 22.96 \%$ and $15.41 \%$ of the DHW energy demand during June, July, August and September, respectively, for Madrid; and 14.5\%, $23.43 \%, 23.40 \%$ and $20.44 \%$ for Seville. These percentages represent a total of $881,4 \mathrm{kWh}$ and $963,77 \mathrm{kWh}$ of energy recovered for Madrid and Seville, respectively, allowing to cover with the $4.96 \%$ and $5.96 \%$ of the DHW energy consumption.

Additionally, when DHW consumption is at $45^{\circ} \mathrm{C}$ and for system B, the DHW energy consumption represents a $30.7 \%$ and $41.46 \%$ of the total energy consumption for Madrid and Seville, respectively. In this case, the MFVRF is able to recover $14.52 \%, 29.83 \%$, $33.44 \%$ and $21.38 \%$ of the DHW energy demand during June, July, August and September, respectively, for Madrid; and a $22.10 \%, 37.44 \%, 37.63 \%$ and $31.86 \%$ for Seville for the same period. Overall, these percentages represent $1249.68 \mathrm{kWh}$ and $1536.08 \mathrm{kWh}$ of energy being recovered for Madrid and Seville, respectively. The total DHW consumption that is finally covered by heat recovery is $6.42 \%$ for Madrid and $8.96 \%$ for Seville.

\section{CONCLUSION}

Building energy simulation is a powerful methodology for assessing the energy impact of buildings. In particular, it enables new solutions to be described and to predict the output of these new alternatives in order to study their feasibility for implementation. 
The present work describes a novel model of the multi-functional variable refrigerant flow (MFVRF) system in EnergyPlus ${ }^{\mathrm{TM}}$, with the purpose of evaluating the energy consumption of this integrated solution in terms of heating, cooling and DHW production in a dynamic simulation environment.

The innovative feature of the presented model is the addition of the DHW production function to the existing EnergyPlus VRF system model, which was the main limitation to achieve the dynamic simulation of the MFVRF system. The proposed approach enables to evaluate the DHW energy consumption and to account for the share of DHW demand that is covered by heat recovery from the MFVRF system, which is essential for the evaluation of energy consumption in buildings and, therefore, for code compliance in Europe.

The developed model has been employed to study the operation of the MFVRF system in a residential building under different climate conditions and DHW consumption temperatures compared to a conventional solution.

Results show that significant energy savings are achieved by the use of the MFVRF system compared to the conventional solution proposed in this work for Madrid $(73.69 \%)$ and for Seville (70.71\%) at a DHW consumption temperature of $45^{\circ} \mathrm{C}$.

Energy consumption is considerably reduced when DHW is consumed at $45^{\circ} \mathrm{C}$, as there is no need for an auxiliary heater in the storage tank. In fact, for the same DHW demand, the consumption of the MFVRF system associated with $\mathrm{DHW}$ production at $45{ }^{\circ} \mathrm{C}$ is considerably lower compared with that of DHW production at $60{ }^{\circ} \mathrm{C}$ for Madrid $(53.0 \%)$ and Seville (59.4\%).

One of the major achievements of the current work is that the developed model enables the calculation of the share of DHW demand that can be covered by heat recovery in a specific building, which is in the range of $4.96 \%$ and $8.96 \%$ for the cases analysed in this paper. It is noteworthy that, in the months with the greatest cooling demand, a substantial part of the demand for DHW can be covered with heat recovery, up to a $37.63 \%$ in the studied cases. Predictably, climates with a higher cooling demand produce more waste heat. It is therefore possible to cover a larger share of the DHW demand by means of heat recovery in climates with a higher cooling demand.

As can be finally justified by the results presented above, the MFVRF system represents a highly efficient solution with considerably lower energy consumption than the proposed conventional system for the case studied. Therefore, as stated in the introduction to this paper, their implementation can be a step towards meeting EU energy efficiency targets in buildings.

\section{References}

1. International Energy Agency, Buildings: A source of enormous untapped efficiency potential (2018).

2. European Parliament, Official Journal of the European Union 153 (2010).

3. European Parliament, Official Journal of the European Union 315 (2012).

4. W. Goetzle, ASHRAE J. 49, 4 (2007).

5. Spanish Technical Code for Energy Saving, Basic Document for Energy Saving (2019).

6. J. Ji, T. Chow, G. Pei, J. Dong, W. He, Appl. Therm. Eng. 23 (2003).

7. S. Shao, W. Shi, X. Jie, Energy Convers. Manag. 45 (2004).

8. M. Jiang, J. Wu, R. Wang, R. Energy Convers. Manag. 52 (2011).

9. U.S. Department of Energy (DOE), EnergyPlus ${ }^{T M}$ Documentation Input Output Reference Version 9.4.0 (2020). 
10. Y. Zhou, J. Wu, R. Wang, S. Shiochi, Energ. Buildings 39 (2007).

11. Y. Zhou, J. Wu, R. Wang, S. Shiochi, Energ. Buildings 40 (2008).

12. Y. Li, J. Wu, S. Shiochi, S., Energ. Buildings 41 (2009).

13. Y. Li, J. Wu, J., Energ. Buildings 42 (2010).

14. R. Raustad, R., ASHRAE Tran 119 (2013).

15. T. Hong, K. Sun, R. Zhang, R. Hinokuma, S. Kasahara, Y. Yura, Energ. Buildings 117 (2016).

16. R. Zhang, K. Sun, T. Hong, Y. Yura, R. Hinokuma, Energ. Buildings 168 (2018).

17. CYPE Software para Arquitectura, Ingeniería y Construcción, IFC Builder (2020).

18. Spanish Technical Association for Air Conditioning and Refrigeration (ATECYR), Technical Guidance: Sanitary Hot Water (2010). 